\title{
An index showing breakdown of seriation, related to disturbance, in a coral-reef assemblage
}

\author{
K. R. Clarke ${ }^{1}$, R. M. Warwick ${ }^{1}$, B. E. Brown ${ }^{2}$ \\ ' Plymouth Marine Laboratory, Prospect Place, West Hoe, Plymouth PL1 3DH, United Kingdom \\ ${ }^{2}$ Centre for Tropical Coastal Management Studies, The University, Newcastle-upon-Tyne NE1 7RU, United Kingdom
}

\begin{abstract}
Intertidal and shallow water reef-corals usually exhibit a regular pattern of change in community structure with increasing water depth. A statistic is developed, the Index of Multivariate Seriation (IMS), which measures the degree to which this community change conforms to a linear sequence. Seriation broke down, and the IMS was reduced, when a coral community at Ko Phuket, Thailand, was subjected to increased disturbance resulting from sedimentation due to offshore dredging. The IMS is suggested as an additional index of community disturbance which might be applied to corals or other shallow-water sessile organisms.
\end{abstract}

KEY WORDS: Community $\cdot$ Corals $\cdot$ Disturbance $\cdot$ Multivariate $\cdot$ Thailand $\cdot$ Zonation

\section{INTRODUCTION}

Clear-cut zonation patterns in the form of a serial change in community structure with increasing water depth are a long-established feature of intertidal and shallow-water benthic communities for both hard and soft substrata (e.g. Stephenson \& Stephenson 1949, Dahl 1952; see Peterson 1991 for a more recent review). In reef-building corals, the causes of these zonation patterns are varied, and may differ according to circumstances, but include environmental gradients such as light or wave energy, competition and predation (reviews by Sheppard 1982, Done 1983). It is not clear, however, that these mechanisms will necessarily give rise to discontinuous bands of different assemblages of coral species, which is implied by the term 'zonation'. Cluster analysis, leading to the representation of site similarities in the form of a dendrogram, has been widely used in the analysis of coral community data (Loya 1972, Maragos 1974, Done 1977, Bradbury \& Young 1981, Tomascik \& Sander 1987); this technique will always find clusters even when in reality there is a continuum of community change, so that conclusions from its widespread use may have overstated the apparent ubiquity of discontinuous zonation. We therefore prefer to use the more general term 'seriation' for a sequential pattern of community change, 'zonation' (with discontinuities) being a special case.

Many of the factors which determine the pattern of seriation are likely to be modified by disturbances of various kinds. For example, dredging may affect the turbidity and sedimentation regimes and major engineering works may alter the wave climate. Elimination of a particular predator may affect patterns which are due to differential mortality of coral species due to that predator, e.g. a damselfish (Wellington 1982). Increased disturbance may also result in the relaxation of interspecific competition (Connell 1978), which may in turn result in a breakdown of the pattern of seriation induced by this mechanism. Where a clear sequence of community change along transects is evident in the undisturbed situation, the degree of breakdown of this sequencing could provide an index of subsequent disturbance. Here we describe a possible index of multivariate seriation, and apply it to a study of the impact of dredging on intertidal coral reefs at Ko Phuket, Thailand. 


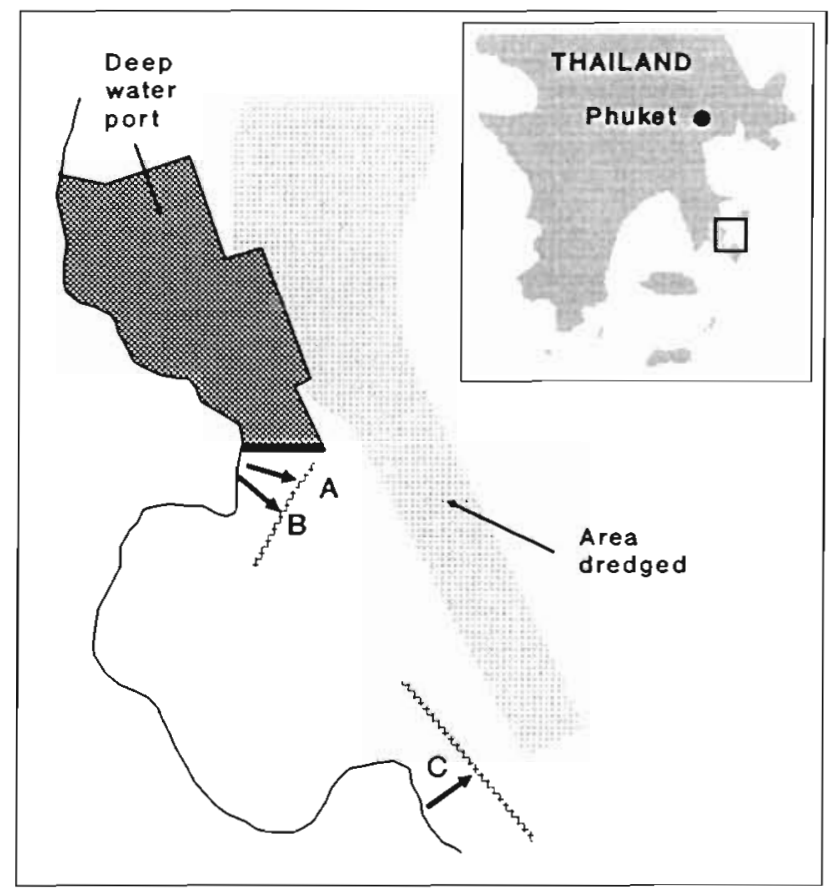

Fig. 1. Study site at Ko Phuket, Thailand, showing locations of Transects $A, B$ \& C

\section{MATERIAL AND METHODS}

Background. The study site, background history and sampling regime have already been detailed elsewhere (Brown et al. 1990). Essentially, in 1986 work began on the construction of a deep-water port on the southeast coast of Ko Phuket (Fig. 1). Sediments for fill were dredged during the establishment of deep-water channels, and during the 10 mo dredging operation over 1.3 million $\mathrm{m}^{3}$ of sediment were transported to the fill site at the port. Fine clay particles escaped through the containing wall of the port into the bay to the south, adding to the more direct increase in sediment loading from the offshore dredging operations. Three transects were established across the coral reefs in this bay (Fig. 1), Transect A being closest to the port, receiving the most sediment, with the nearby Transect $B$ expected to be somewhat less impacted. Transect $C$ was some $800 \mathrm{~m}$ away from the port, situated on the edge of a channel where tidal currents carry sediment plumes away from the reef (Ditlev 1978), and received relatively low levels of sediment as a result of the dredging operation. Although the coral community, particularly the dominant species Porites lutea, suffered considerable partial mortality as a result of the increased sedimentation, surviving colonies of this species did not reflect this event in terms of an interruption to skeletal growth (Brown et al. 1990).
Sampling. Surveys of these 3 transects, perpendicular to the shore, were conducted in 1983, 1986, 1987 and 1988. Plotless line samples $10 \mathrm{~m}$ long fyielding estimates of coral cover via 1-dimensional sampling; Loya 1978) were placed parallel to the shore at $10 \mathrm{~m}$ intervals along the perpendicular transect from the inner reef flat to the outer reef edge, 12 lines along each of Transects A \& C and 17 along Transect $\mathrm{B}$. The transects were permanently marked and exactly relocated each year. Living coral cover (m) of each species and the total number of colonies of each species were recorded. Transect C was not surveyed in 1986.

Data analysis. The basic data were root-transformed so that the ensuing multivariate ordinations were not determined only by the most dominant species (Clarke \& Green 1988). Bray-Curtis similarities (Bray \& Curtis 1957) were then calculated between every pair of samples within each year/transect combination. This coefficient is commonly used for species counts (Field et al. 1982) and has also been employed for data on coral species cover (Warwick et al. 1990). It belongs to a small class of coefficients which have both desirable theoretical properties and robust practical performance for ecological data (Faith et al. 1987, Clarke 1993).

The resulting triangular similarity matrices were then input to an ordination routine, non-metric multidimensional scaling (MDS, e.g. Kruskal \& Wish 1978). This displays the 12 (or 17) samples from a year/transect combination as points in 2 dimensions, with a perfect ordination (zero stress) resulting in inter-point distances having the same rank order as the corresponding pairwise dissimilarities between samples. Experiences with the MDS algorithm in ecological contexts are detailed in Field et al. (1982) and Clarke (1993), and Kenkel \& Orloci (1986) and Minchin (1987) use simulation studies to demonstrate its theoretical advantages. Several practical examples of its application in pollution or disturbance studies can be found in the marine ecology literature (e.g. Gee et al. 1985, Gray et al. 1990, Dawson-Shepherd et al. 1992, Agard et al. 1993, Warwick 1993. Warwick \& Clarke 1993 and a number of papers in special issues of journals reporting the results of IOC/GEEP workshops on the biological effects of pollution: Bayne et al. 1988, Addison \& Clarke 1990, Stebbing et al. 1992).

By joining the points in an MDS, in the order of the samples along the offshore transect, one can visualise the degree of seriation, i.e. the extent to which the community changes in a smooth and regular fashion, departing ever further from its state at the start of the transect. To aid the visual comparison, the MDS plots in Fig. 2 (discussed more fully in 'Results') have all been rotated to have the furthest inner reef sample to the left of the configuration; note that scaling, reflection and orientation are arbitrary for an MDS plot. 
A measure of linearity of the resulting sequence could be constructed directly from the location of the points in the MDS. However, this could be misleading when the stress is not zero, i.e. the full pattern of relationships between the samples cannot be perfectly represented in 2 dimensions; this will often be the case, as with some of the component plots in Fig. 2. In an analogous situation, relating community pattern to associated environmental variables, Clarke \& Ainsworth (1993) argue that a more satisfactory approach is to work with the fundamental similarity matrix that underlies the MDS plots, of whatever dimension. The index of multivariate seriation (IMS) proposed here is therefore defined as a Spearman rank correlation coefficient ( $\rho_{s}$, e.g. Kendall 1970) computed between the corresponding elements of 2 triangular matrices of 'dissimilarities'. The first is that of BrayCurtis coefficients calculated for all pairs from the $n$ coral community samples ( $n=12$ or 17 in this case). The second is simply the inter-point distances of $n$ points laid out, equally spaced, along a line. If the community changes exactly match the ranking in this linear sequence (for example, Sample 1 is close in species composition to Sample 2, Samples 1 and 3 are less similar, 1 and 4 less similar still, up to 1 and 12 having the greatest dissimilarity) then the IMS takes the value 1. If, on the other hand, there is no discernible biotic pattern along the transect, or if the relationship between the community structure and distance offshore is very non-monotonic - with the composition being similar at opposite ends of the transect but very different in the middle - then the IMS will be close to zero. These near-zero values can be negative as well as positive but no particular significance attaches to this.

A statistical significance test would clearly be useful to answer the question: when is the IMS sufficiently different from zero to reject the null hypothesis of a complete absence of seriation? Such a test can be derived by a Monte Carlo permutation procedure. If the null hypothesis is true then the labelling of samples along the transect $(1,2, \ldots, n)$ is entirely arbitrary, and the spread of IMS values which are consistent with the null hypothesis can be determined by recomputing it for all possible permutations of the sample labels in 1 of the 2 similarity matrices (holding the other fixed). In practice, there will usually be too many possibilities to perform a full evaluation, so the permutation distribution is sampled from by a Monte Carlo procedure (Hope 1968). For $M$ randomly selected permutations of the sample labels, if only $m$ of the $M$ simulated IMS values are greater than or equal to the observed IMS, the null hypothesis can be rejected at a significance level of $100(m+1) /(M+1) \%$.
In structure, the test is equivalent to that considered by Clarke \& Ainsworth (1993) for linking biotic community pattern to a matrix of environmental variables, in this case there being only one 'environmental' variable, the linear sequence $(1,2, \ldots, n)$. The test also arises, in another guise, in Clarke \& Warwick (1993), where it is used to examine 2 (or more) community patterns for evidence of common biotic structure. One distinctive feature of the current test is that tied ranks will be numerous, particularly in the similarities computed from the linear sequence, and it is advisable to make proper allowance for this in calculating the Spearman coefficients. Kendall (1970, Eq. 3.7) gives an appropriate adjustment to $p_{s}$, and this form is used in the analysis that follows.

\section{RESULTS}

In 1983, before the dredging operations, MDS configurations (top row of Fig. 2) indicate that the points along each transect conform rather closely to a linear sequence, and there are no obvious discontinuities in the sequence of community change (i.e. no discrete clusters separated by large gaps); the community change follows a quite gradual pattern. The values of the IMS are consequently high (Table 1), and the correlation with a linear sequence is strongly significant in all 3 cases. For example, Fig. 3a shows the histogram of expected IMS values in the absence of seriation, for Transect A in 1983. The largest of the $M=999$ simulations is 0.43 , well short of the observed correlation of 0.65 , so that the null hypothesis is rejected at least at the $\mathrm{p}<0.1 \%$ level. Note that in the 1983 MDS for transect A (Fig. 2) the furthest inshore sample has been omitted; it had very little coral cover and was an outlier on the plot, resulting in an unhelpfully condensed display of the remaining points. (This is to be expected in MDS analyses where one sample has a higher dissimilarity to all other samples than any other dissimilarity in the matrix - see Clarke 1993 and the MDS needs to be replotted with this point removed.) There is no similar technical need, however, to remove this sample from the IMS calculation - this was not done in Fig. 3 a or Table 1 for example - though doing so would increase the $\rho_{\mathrm{s}}$ value from 0.65 to 0.74 (as indicated in Fig. 2).

On Transect $A$, subjected to the highest sedimentation, visual inspection of the MDS configurations gives a clear impression of the breakdown of the linear sequence for the subsequent 2 sampling occasions. The IMS is dramatically reduced to 0.26 in 1986 , when the dredging operations commenced, although the correlation with a linear sequence is still just significant ( $\mathrm{p}=3.8 \%$ ). By 1987 the IMS on this transect is further reduced to 0.19 and the correlation with a linear 


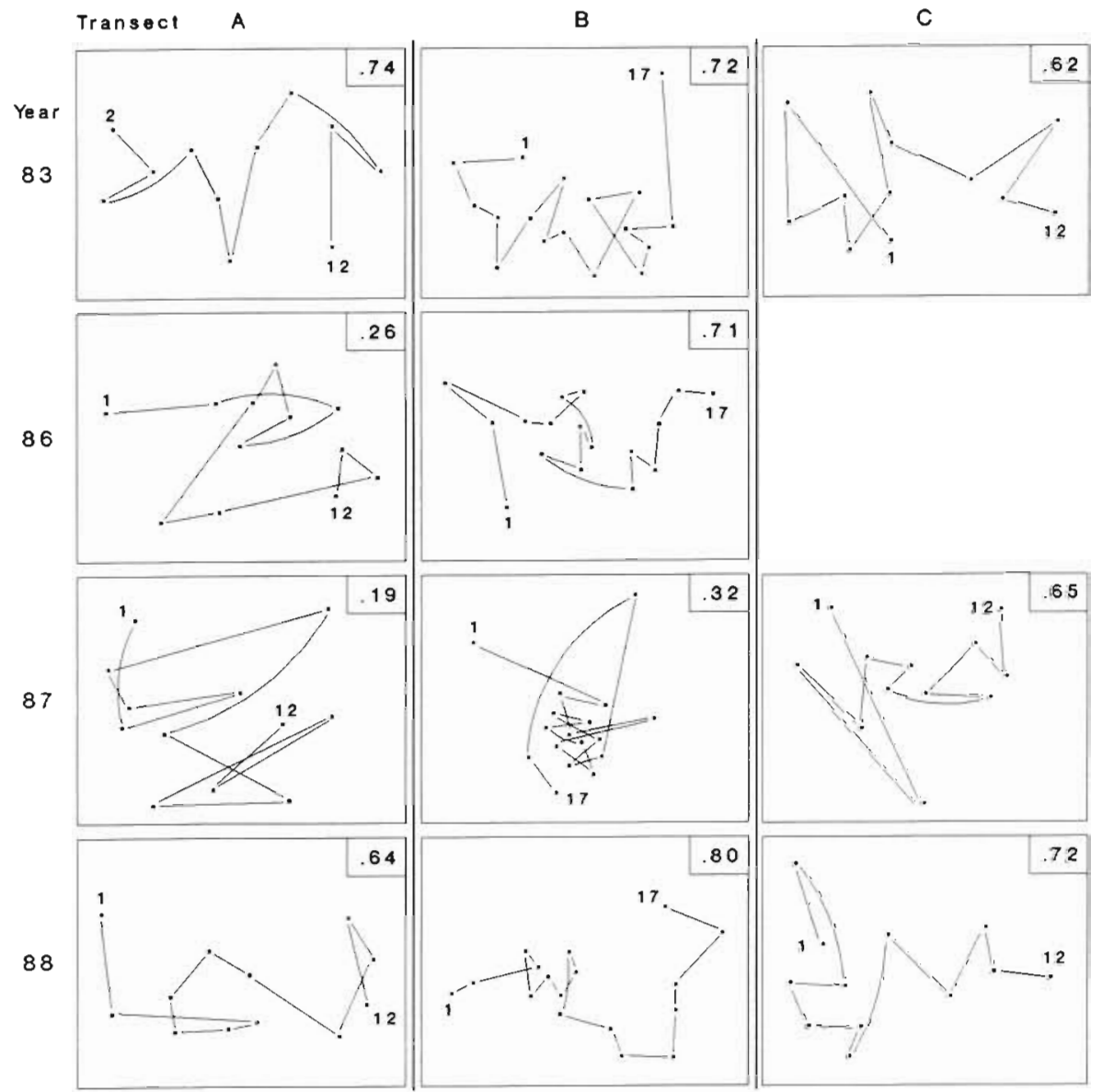

Fig. 2. Multi-dimensional scaling (MDS) ordination in 2 dimensions of the changing coral communities along 3 transects (A to $C$ ) at 4 times (1983 to 1988), based on BrayCurtis similarities from root-transformed data on species cover. The lines indicate the degree of seriation by linking successive points along a transect, from onshore (1) to offshore samples (12 or 17); Sample 1 from Transect A in 1983 is omitted (see text) and no samples were taken for Transect C in 1986. Corresponding Index of Multivariate Seriation (IMS) values are given in the top-right boxes (from Table 1, but note that the value for Transect A in 1983 now excludes Sample 1). Stress values, reading across rows, are: $0.10,0.11,0.09_{i}$ $0.10,0.11 ; 0.08,0.14,0.11 ; 0.07$, $0.09,0.10$ sequence is no longer significant at the $5 \%$ level; 63 of the 999 simulations are now as large as the observed value $(p=6.4 \%)$, see Fig. $3 \mathrm{~b}$. The latter figure also demonstrates the advisability of simulating the full distribution of the IMS statistic for each separate test, rather than attempting some form of normal approximation to the tail-area probability: in spite of the fact that the 1983 and 1987 data involve the same number of samples, the Spearman coefficient has a rather different null distribution in the 2 cases (Fig. 3a, b).

Table 1 Index of Multivariate Seriation (IMS) along the 3 transects and for 4 sampling occasions. (Note that the value for Transect A in 1983 includes Sample 1; see text.) Values in parentheses are the \% significance levels based on a permutation test for absence of seriation ( $M=999$ simulations)

\begin{tabular}{|cccc|}
\hline Year & \multicolumn{3}{c|}{ Transect } \\
& $\mathrm{A}$ & $\mathrm{B}$ & $\mathrm{C}$ \\
\hline 1983 & $0.65(0.1 \%)$ & $0.72(0.1 \%)$ & $0.62(0.1 \%)$ \\
1986 & $0.26(3.8 \%)$ & $0.71(0.1 \%)$ & - \\
1987 & $0.19(6.4 \%)$ & $0.32(0.2 \%)$ & $0.65(0.1 \%)$ \\
1988 & $0.64(0.1 \%)$ & $0.80(0.1 \%)$ & $0.72(0.1 \%)$ \\
\hline
\end{tabular}

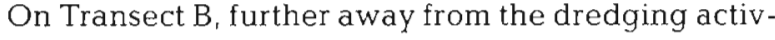
ity, the loss of seriation is not evident until 1987, when the sequencing of points on the MDS configuration breaks down and the IMS is reduced to 0.32 , although the latter is still significant ( $p=0.2 \%)$. When comparing IMS values across the component plots of Fig. 2, it is important to bear in mind that the MDS configurations may not tell the whole story; the stress values lie between 0.07 and 0.14 , indicating that the 2-dimensional pictures are not perfect representations of the full inter-sample relationships (though unlikely seriously to mislead, e.g. Clarke 1993). The largest stress is, in fact, that for Transect B in 1987, so that the seriation that is still detectable by the test is only imperfectly seen in the 2-dimensional plot. Closer perusal of the rank similarities shows that samples $1,2,3, \ldots$ etc. аге very different in community structure from points at the other end of this transect. In comparison, the plot for Transect A in 1986, for example, has a correspondingly lower IMS value $(0.26)$ because Samples $3 \& 5$ do have some compositional similarity to the end-point samples 10 to 12 (note that the stress is also lower for the latter plot, and the MDS therefore a more reliable picture). The lowest IMS value overall $(0.19)$ is for 

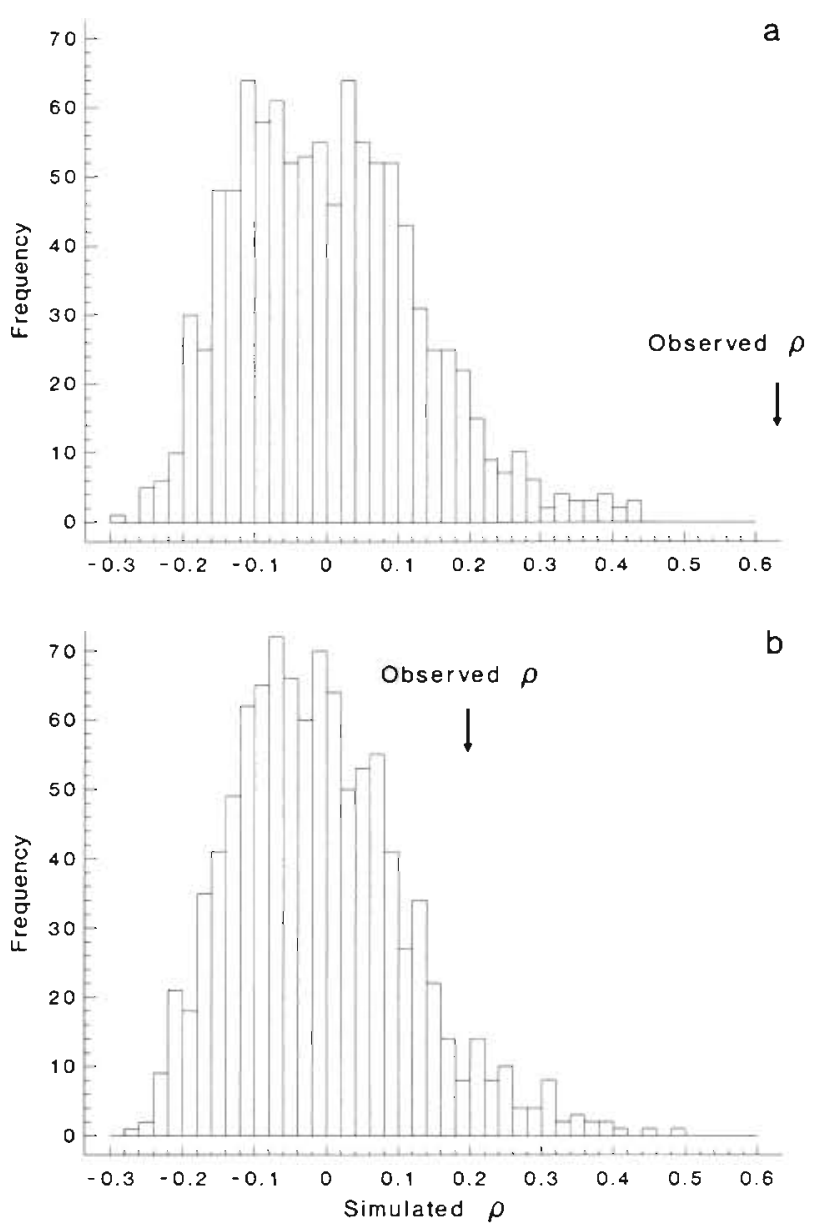

Fig. 3. Histograms of simulated IMS values from 999 random permutations of the sample labels (under the assumption of no seriation), for Transect $A$ in (a) 1983 and (b) 1987 The real correlations observed were $0.65(\mathrm{p}<0.1 \%)$ and $0.19(\mathrm{p}=$ $6.4 \%$ ) respectively

Transect A in 1987; this is commensurate with the visual message of the plots: situations in which communities from widely separated points on the transect can be rather similar, and composition for adjacent points very different, are precisely those for which the index would be expected to be smallest.

With regard to significance levels associated with particular IMS values, it should also be noted that the increased number of points (17) on Transect $B$, in comparison with Transects A \& C (12), will lead to a more sensitive test. The spread of correlation values under the hypothesis of 'no seriation' will be tighter for Transect $B$ than that seen in Fig. 3. For example, the values have a maximum of 0.34 in 999 simulations of Transect $\mathrm{B}$ in 1987, compared with 0.49 for Transect $A$ in that year.

On Transect $C$ there is no evidence of the breakdown of seriation at all, either from the IMS values or from inspection of the MDS plot. By 1988, Transects A
\& B had completely recovered their seriation pattern, with IMS values equal to or higher than their 1983 values, highly significant correlations with a linear sequence ( $p<0.1 \%$ ) and clear sequencing evident on the MDS plots. There was clearly a graded response, with a greater breakdown of seriation occurring earlier on the most impacted transect, some breakdown on the middle transect but no measurable breakdown at all on the least impacted transect.

\section{DISCUSSION}

Breakdown of seriation was clearly not an artifact resulting from increased sampling variability due to lower cover per species, because no such reductions in cover occurred. For example, comparing the most impacted transect (A) in 1983 with 1987 (see Table 2 for the raw data), the number of species was reduced from 31 to 15 , the total cover was reduced from $38.7 \mathrm{~m}$ to $21.3 \mathrm{~m}$, and average cover per species remained roughly stable at $1.25 \mathrm{~m}$ and $1.42 \mathrm{~m}$ respectively. Neither did the seriation break down simply through loss of species confined to the lower shore (Samples 6 to 12 ) in 1983. For Transect $A$, when only the 10 species still present in 1987 were used in the analysis of the 1983 distribution, the IMS value remained high $(0.63$ compared with 0.65 for the full species set). Of these 10 species, a combination of just 4 species generated an IMS of 0.69 in 1983 and so these were clearly the main species responsible for seriation prior to the disturbance. By 1987 the dominant Porites lutea had increased in total cover, from $6.9 \mathrm{~m}$ to $10.1 \mathrm{~m}$, and had marginally widened its distributional range. The other 3 species, Goniastrea retiformis, Favites abdita and Favia pallida, more than halved in cover, and there is some evidence for all 3 increasing their range but becoming more patchy within it. Two other species not particularly implicated in the seriation pattern in 1983, Leptastrea transversa and Goniastrea aspera, increased in both total cover and distributional range. Goniastrea favulus and Coeloseris mayeri suffered a dramatic (10-fold) reduction in cover but with no obvious change in range. The remaining 3 species were not sufficiently abundant in either 1983 or 1987 for any conclusions about changes in distribution to be drawn.

Overall, then, the breakdown in the pattern of seriation between 1983 and 1987 appears to be due to the increase in distributional range of species which were previously confined to distinct sections of the shore. This is commensurate with the disruption of almost all the types of mechanism which have been invoked to explain patterns of seriation (see 'Introduction'), and gives us no clue as to which of these is the likely cause. 


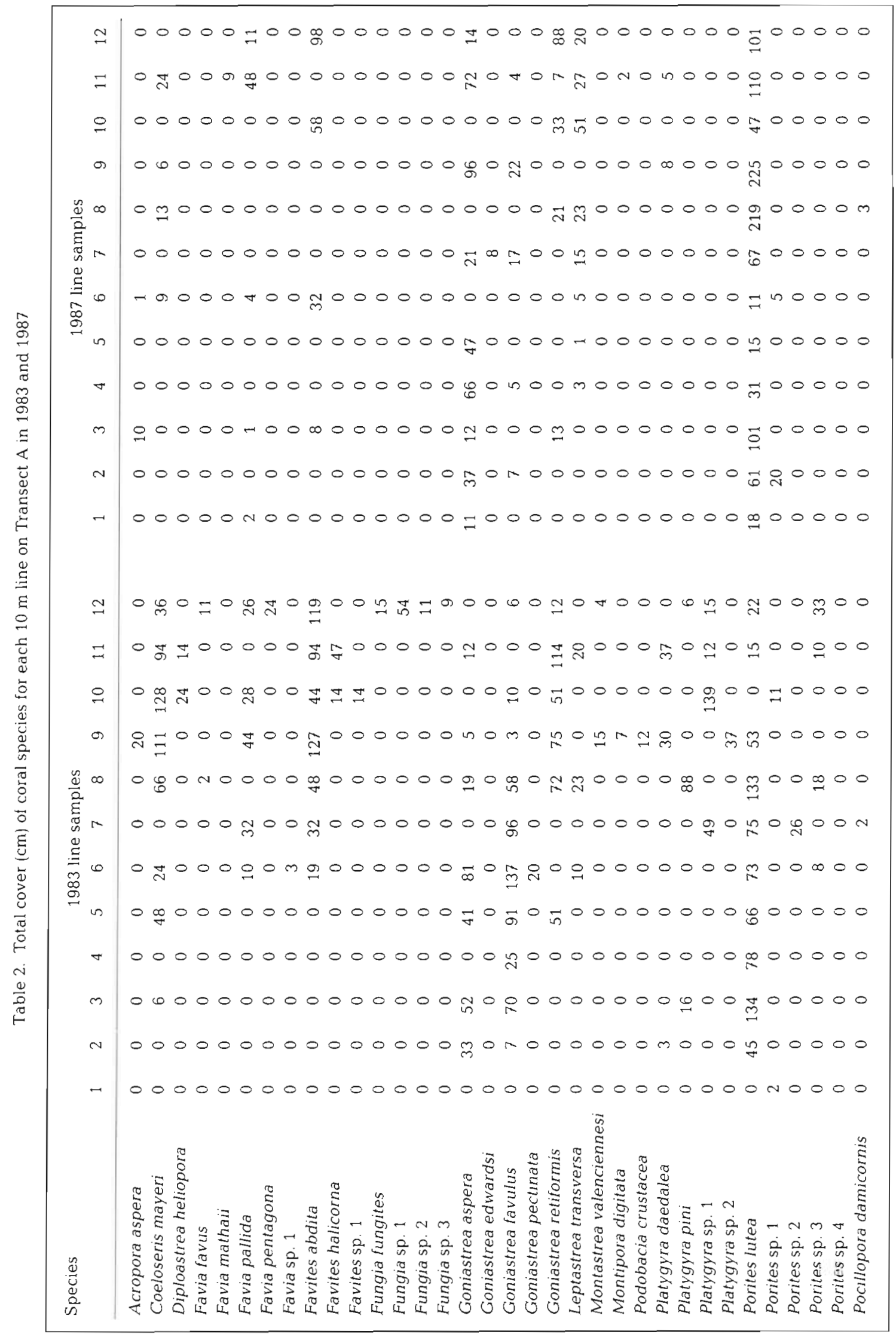


The use of ordination techniques to display change in coral communities is not novel, for example Wallace \& Dale (1977) described the application of Principal Co-ordinates Analysis in a study of zonation patterns. However, the extension to computation of a seriation measure, in the context of an ordination method (nonmetric MDS) increasingly favoured for its robust properties, appears a potentially versatile development, and might well be applied to other sessile organisms which exhibit spatial seriation in shallow water.

There are a number of reasons for preferring to base the index on the similarity matrix underlying the MDS, rather than by attempting some type of fit of the ordination co-ordinates to a straight line. One reason has already been pointed out: the avoidance of arbitrariness in selection of the ordination dimensionality within which to work; it is rarely clear what the 'correct' MDS dimension should be. There is also good reason to suppose that a similarity-based approach will capture seriation equally well in cases where the 2dimensional ordination shows a strong 'horseshoe effect'. The latter will tend to confuse any linear sequence statistic based on direct inference from the configuration co-ordinates, yet it is a common artifact of an ordination which is highly 1-dimensional (i.e. truly serial) when represented in 2-dimensional space (e.g. Seber 1983).

This also raises the question of the power of the permutation test to demonstrate presence of seriation, i.e. a significant departure from the null hypothesis. Formal power analysis is likely to be precluded by the usual difficulties of delimiting appropriate alternative hypotheses, for complex multivariate data handled non-parametrically. Clearly, though, the test becomes rapidly more sensitive as the sample size increases, there being ( $n$ !)/2 distinct permutations for $n$ transect points. The situation is further complicated by the presence of tied ranks, but a $5 \%$ significance level test should therefore be possible for $n$ as low as 5 , though this would detect only the most regimented examples of seriation. Sample sizes of at least double this number would seem advisable in practical studies.

Finally, note that the similarity-based formulation, and the associated permutation test, are readily extendable to more complex models than a linear sequence of change along a spatial transect. In a homologous way, community change could be related to a temporal trend or cyclicity, or to the sampling positions in a 2-dimensional spatial layout; such developments will be the subject of a further report.

Acknowledgements. We thank the anonymous referees for helpful comments. This work forms part of the Community Ecology project of the Plymouth Marine Laboratory.

\section{LITERATURE CITED}

Addison, R. F., Clarke, K. R. (eds.) (1990). Biological effects of pollutants in a subtropical environment. J. exp. mar. Biol. Ecol. 138: 1-166

Agard, J. B. R., Gobin, J., Warwick, R. M. (1993). Analysis of marine macrobenthic community structure in relation to pollution, natural oil seepage and seasonal disturbance in a tropical environment (Trinidad, West Indies). Mar. Ecol. Prog. Ser. 92: 233-243

Bayne, B. L., Clarke, K. R., Gray, J. S. (eds.) (1988). Biological effects of pollutants: results of a practical workshop. Mar. Ecol. Prog. Ser. 46: 1-278

Bradbury, R. H., Young, P. C. (1981). The effects of a major forcing function, wave energy, on a coral reef ecosystem. Mar. Ecol. Prog. Ser. 5: 229-241

Bray, J. R., Curtis, J. T. (1957). An ordination of the upland forest communities of Southern Wisconsin. Ecol. Monogr. 27: $325-349$

Brown, B. E., Le Tissier, M. D. A., Scoffin, T P., Tudhope, A. W. (1990). An evaluation of the environmental impact of dredging on intertidal coral reefs at Ko Phuket, Thailand, using ecological and physiological parameters. Mar. Ecol. Prog. Ser. 65: 273-281

Clarke, K. R. (1993). Non-parametric multivariate analyses of changes in community structure. Aust. J. Ecol. 18: 117-143

Clarke, K. R., Ainsworth, M. (1993). A method of linking multivariate community structure to environmental variables. Mar. Ecol. Prog. Ser. 92: 205-219

Clarke, K. R. Green, R. H. (1988). Statistical design and analysis for a 'biological effects' study. Mar Ecol. Prog. Ser. 46: 213-226

Clarke, K. R., Warwick, R. M. (1993). Similarity-based testing for community pattern: the 2-way layout with no replication Mar. Biol. (in press)

Connell, J. H. (1978). Diversity in tropical rain forests and coral reefs. Science 199: 1302-1310

Dahl, E. (1952). Some aspects of the ecology and zonation of the fauna on sandy beaches. Oikos 4: 1-27

Dawson-Shepherd, A. R., Warwick, R. M., Clarke, K. R., Brown, B. E. (1992). An analysis of fish community responses to coral mining in the Maldives. Environ. Biol. Fish. 33: $367-380$

Ditlev, H. (1978). Zonation of corals (Scleractinia: Coelenterata) on intertidal reef flats at Ko Phuket, Eastern Indian Ocean. Mar. Biol. 47: 29-39

Done, T. J. (1977). A comparison of units of cover in ecological classifications of coral communities. Proc. 3rd Int. Symp. Coral Reefs 1: 9-14

Done, T. J. (1983). Coral zonation: its nature and significance. In: Barnes, D. J. (ed.) Perspectives on coral reefs. Australian Institute of Marine Science, Townsville, p. 107-147

Faith, D. P., Minchin, P. R., Belbin, L. (1987). Compositional dissimilarity as a robust measure of ecological distance. Vegetatio 69: 57-68

Field, J. G., Clarke, K. R., Warwick, R. M. (1982). A practical strategy for analysing multispecies distribution patterns. Mar. Ecol. Prog. Ser. 8: 37-52

Gee, J. M., Warwick, R. M., Schaanning, M., Berge, J. A., Ambrose Jr., W. G. (1985). Effects of organic enrichment on meiofaunal abundance and community structure in sublittoral soft sediments. J. exp. mar. Biol. Ecol. 91: $247-62$

Gray, J. S., Clarke, K. R., Warwick, R. M., Hobbs, G. (1990). Detection of the initial effects of pollution on marine benthos: an example from the Ekofisk and Eldfisk oilfields, North Sea. Mar. Ecol. Prog. Ser. 66: 285-299 
Hope, A. C. A. (1968). A simplified Monte Carlo significance test procedure. J. R. statist. Soc. Ser. B 30: 582-98

Kendall, M. G. (1970). Rank correlation methods. Griffin, London

Kenkel, N. C., Orloci, L. (1986). Applying metric and nonmetric multi-dimensional scaling to some ecological studies: some new results. Ecology 67: 919-28

Kruskal, J. B., Wish, M. (1978). Multidimensional scaling Sage Publications, Beverley Hills, CA

Loya, Y (1972). Community structure and species diversity of hermatypic corals at Eilat, Red Sea. Mar. Biol. 13: 100-123

Loya, Y (1978). Plotless and transect methods. In: Stoddart, D. R. Johannes, R. E. (eds.) Coral reefs: research methods UNESCO, Paris, p. 197-217

Maragos, J. E. (1974). Coral communities on a seaward reef slope, Fanning Island. Pacif. Sci. 28: 257-278

Minchin, P. R. (1987). An evaluation of the relative robustness of techniques for ecological ordination. Vegetatio 69: 89-107

Peterson, C. H. (1991). Intertidal zonation of marine invertebrates in sand and mud. Am. Sci. 79: 236-249

Seber, G. A. F. (1983). Multivariate observations. Wiley, New York

Stebbing, A. R. D., Dethlefsen, V., Carr, M. (eds.) (1992). Biological effects of contaminants in the North Sea. Mar. Ecol. Prog. Ser. 91: 1-361

This article was submitted to the editor
Sheppard, C. R. C. (1982). Coral populations on reef slopes and their major controls. Mar. Ecol. Prog. Ser. 7: 83-115

Stephenson, T A., Stephenson, A. (1949). The universal features of zonation between tide marks on rocky coasts. J. Ecol. 37: 289-305

Tomascik, T., Sander, F. (1987). Effects of eutrophication on reef-building corals. II. Structure of scleractinian coral communities on fringing reefs, Barbados, West Indies. Mar. Biol 94: 53-75

Wallace, C. C., Dale, M. B. (1977). An information analysis approach to zonation patterns of the coral genus Acropora on outer reef buttresses. Atoll Res. Bull. 220: 95-110

Warwick, R. M. (1993). Environmental impact studies on marine communities: pragmatical considerations. Aust. J. Ecol. 18: $63-80$

Warwick, R. M., Clarke, K. R. (1993). Comparing the severity of disturbance: a meta-analysis of marine macrobenthic community data. Mar. Ecol. Prog. Ser. 92: 221-231

Warwick, R. M., Clarke, K. R., Suharsono (1990). A statistical analysis of coral community responses to the 1982-83 El Niño in the Thousand Islands, Indonesia. Coral Reefs 8: $171-179$

Wellington, G. M. (1982). Depth zonation of corals in the Gulf of Panama: control and facilitation by resident reef fishes. Ecol. Monogr. 52: 223-241

Manuscript first received: May 19, 1993

Revised version accepted: August 30, 1993 